\title{
The use of multimedia language laboratory in teaching English phonetics at the university
}

\author{
E.N. Kvasyuk ${ }^{1 *}$, O.V. Putistina ${ }^{2}$, and $O . V$. Savateeva ${ }^{3}$ \\ ${ }^{1}$ Murmansk Arctic State University,Murmansk, Russia \\ ${ }^{2}$ Murmansk Arctic State University,Murmansk, Russia \\ ${ }^{3}$ Murmansk Arctic State University,Murmansk, Russia
}

\begin{abstract}
The importance of correct English pronunciation is growing due to its central role in communication and the speaker's identity. Nonnative English speakers lack a natural linguistic environment and tend to carry articulation rules and intonation from their mother tongue. Modern conditions of the fast-paced world require a revision of the forms and methods of the educational process. Teachers should engage students in independent and individual work at classes, increase the use of practical and research tasks. Information technologies in the teaching process at different levels of education (both school and university) change the roles of all participants in the educational process. Thus, teachers are given more opportunities to improve their work, and students are taught a foreign language at a higher level. The article aims to state the advantages of using multimedia technologies as an educational tool in teaching English practical phonetics and to find out university students' attitude to it. The object of the research is the benefits of working in a language laboratory, equipped with Rinel-Lingo (a multimedia language programme to train phonetics of a foreign language of university students). The article analyzes the results of the survey conducted in Murmansk arctic state university.
\end{abstract}

\section{A problem statement}

This article is motivated by the topicality of the problem of teaching English phonetics with the help of multimedia technologies. In the modern world of great scientific and technological progress, people should be able to search for necessary information which has become one of the main tools in any sphere of human activity. Learning foreign languages is not an exception. Much of the literature concerning methods of teaching English at the university does not focus on the use of a language laboratory. In contrast, the primary aim of this article is to illustrate some strategies and results of teaching practical phonetics of the English language with the help of multimedia technologies. Using these tools at English classes also helps master language competence and intercultural communication of students.

\footnotetext{
*Corresponding author: prof-ped.gpa@mail.ru
} 
Multimedia technologies are understood as a combination of computer technologies that use several types of information at the same time: graphics, text, video, photos, animation, sound effects, and sound.

One of the main difficulties of mastering English phonetics is the lack of a natural linguistic environment at Russian educational institutions and the necessity to create the artificial one. Various innovative teaching tools, one of which is a language laboratory, can help solve this problem. Learners can be completely immersed in the linguistic environment with the help of infinite opportunities of multimedia language laboratories with various sound and visual effects, access to the Internet, a great number of listening and speaking activities.

Based on the analysis of the survey results of 50 second-year students of Murmansk arctic state university, the author examines the efficiency of the used teaching techniques. The findings support the prediction of the benefits of multimedia technologies in teaching practical phonetics of the English language.

\subsection{The objective of the work}

Communication in any form (in foreign and native language) is based on a good command of the sound structure of the language, the correct pronunciation, and speakers' culture of the voice. When the speaker violates the norms of pronunciation or when the listener lacks necessary phonation skills, the speech addressed to him will not be understood fully. The normal functioning of oral speech activity in dialogical and monological form can be successful (can help exchange information and gain mutual understanding) in terms of the formation of stable norms of pronunciation and phonation culture of both communicating partners. An internally formed thought is externally voiced with the help of phonetic and phonation skills, verbal and non-verbal means in any speech activity.

The approaches to teaching phonetics of the English language have been studied in detail by many Russian and foreign scientists in their works: V. Zavyalova, P. Ashby, J.K. Chambers \& P. Trudgill, A.P.R. Howartt, H.A. Sweet, and others [1, 2, 3, 4, 5].

Let us have a look at the stages that the process of forming a pronunciation skill goes through [6].

1. Perception - when the right sound (auditory) image is created.

2. Differentiation - when the signs of a sound are understood and distinguished.

3. Imitation - when speech images of a speech unit are consolidated.

4. Isolated reproduction - when articulation based on the use of pronunciations is consolidated.

5. Combination - when attention from one phonetic phenomenon is switched to the other.

Any type of speech activity is based on sound substance (as its primary element) and auditory-pronunciation skills. Therefore, work on pronunciation starts from the basic stage, and then extends to the entire course of learning a foreign language. In the first year of university, students of the linguistic department (future linguists and teachers of foreign languages) have a special practical course of phonetic skills development; during the following years of studying, these skills are practiced and nailed down. If at the initial stage of professional education incorrect pronunciation habits are not amended, it can be very difficult to correct them later.

There are some ways of teaching practical phonetics to first-year university students. One of them is analytic-imitative which is considered to be the most efficient in pronunciation training. The phonetic material is sequenced according to the needs of communication. Sounds of the foreign language are singled out, their articulation rules are explained, analyzed, and compared with phonemes of the native language. The most 
difficult phonemes (that have no counterparts in the native language) are introduced and practiced separately. At the next stage, various combinations of sounds are studied gradually: syllables, words, word combinations, phrases, sentences, and texts. Students practice imitation of single sounds and their combinations, based on the theoretical background. The pronunciation features of the sounds are usually demonstrated in a visual, somewhat exaggerated way. Then follows the intensive training of students in pronunciation, which again takes place on the basis of standards [4].

Efficient development of practical phonetic skills of the first-year university students should comprise such forms of work as practicing phonetic drills to exercise the articulation of phonemes both in separate position and in sound combinations; reading aloud to practice articulation, sentence stress and intonation of foreign speech; paying attention to the phonetic side of the new lexical material and grammar structures. Teachers usually include phonetic exercises in Practical Phonetics lessons in levels (initially, separate phonemes, then in various combinations, words, sentences, and texts). Regular phonetic drilling will help prevent the deautomatization of pronunciation skills and improve knowledge.

Indicators of the formation of phonetic skills of oral speech activity are the following: correctly pronounced sounds in the speech stream, clear English articulation, intonationoriented oral communication according to the communicative types, observance of the melodic pattern, correctly performed phrasal and verbal stress, fluent speaking at a normal pace for perception [7].

Teachers can evaluate the formation of a student's phonation skills according to some factors:

- good utterance and intonation,

- emotional colouring, according to the communicative task and extra-linguistic situation,

- logical stress of the words in the phrase,

- appropriate expressiveness of speech and its dynamics,

- rational pauses and breathing.

According to the opinion of scientists [2, 3], rhythm and intonation of speech have a semantic-forming function, making up the structural unity of melody, rhythm, and tempo, having one or another communicative value. If a person lacks these skills it influences the process of sense-expression in speaking and sense-perception in the perception of sounding speech by communication partners. Since phonetic exercises are purely linguistic, many teachers find it impossible to practice articulation and intonation of a foreign language in connection with oral communication.

Being the reality of our time, innovative educational methods, and techniques that are used in classes can solve the mentioned problem. Various multimedia educational tools are considered to be the most efficient in teaching foreign languages and we should take advantage of their opportunities [8, 2, 9]. Firstly, they help students progress quicker and improve their knowledge of the language. The learning process is enriched by the use of multimedia tools; most of the sensory components of students are involved in the process of perceiving necessary information. Secondly, information technologies boost the communicative skills and develop students' creative and cognitive abilities. Thirdly, conditions of real speech communication in foreign languages can be created with the help of multimedia teaching tools $[8,10,11,12]$.

However, the use of multimedia educational technologies can affect negatively the teaching process at the university:

- linguistic computer programmes are usually inappropriate for the level of university students;

- teachers can lack computer literacy and face the difficulties of operating the multimedia classroom; 
- students can risk their health due to prolonged computer time;

- learners can lack interpersonal communication.

The integration of multimedia technologies into studying in secondary and higher educational institutions has changed the ideology of thinking. Recently the teacher used to be the center of the educational process and students had to follow his/her instructions, playing a passive role in such a training model. The main aim of education was to transfer knowledge. Nowadays a new technology of teaching is used, where the students play the key role; they actively cooperate and collaborate in classes. The aim of teaching English now is to develop students' communicative competence and self-learning abilities.

A multimedia lesson is intended for the implementation of various goals, such as: to learn new material; to present new information and broaden the horizons of students; to develop necessary skills; to revise the material; to apply acquired knowledge and skills in practice $[10,9]$.

Among multimedia tools that are used at English lessons, we can list the following: an interactive board; a multimedia screen; interactive questionnaires and quizzes; online educational programs; simulation technology; diagnostic complexes. In our article, we are going to study the benefits of using multimedia language laboratories in the process of studying English phonetics at university.

Language laboratories are considered to be the most efficient multimedia tool for teaching English practical phonetics $[11,12,6,13]$. A special executive system that is used in a language laboratory serves to create an artificial linguistic environment that is very beneficial for the development of communicative language skills.

Language laboratories in Murmansk arctic state university are equipped with a Rinellingo system that implements advanced audio communication features. They allow the teacher of Practical English Phonetics to create arbitrary audio groups, which is especially effective when learning phonetics of the English language. The pronunciation becomes visualized and is perceived faster and easier. Adjusting the speed of sound allows each student to individually split phrases into separate words, thereby training difficult and challenging areas, allowing you to compare pronunciation and spelling of words. Using the Rinel-Lingo software or the Rinel-Lingo Audio kit in a computer classroom, teachers and students can communicate with each other in audio groups arbitrarily created by the teacher. Members of one audio group can maintain a constant audio connection between them and hear the sounds generated by their computer and the computers of other members of this group. However, members of one audio group do not hear members of other audio groups. The teacher also has the opportunity to make a message via speakerphone for students who took off their headphones.

The language laboratory consists of the following components:

- Rinel-Lingo software;

- Rinel-Lingo Audio audio switch;

- video switch Rinel-Lingo Video;

- linguaphone specialized tables-cabins;

- soundproofing partitions made of plexiglass;

- computers in every workplace.

Audio communication when using the switch is implemented by software methods using a special audio network. The quality of audio communication is maintained at a consistently high level and does not depend on the software used, configuration, load, capacity of computers, and bandwidth of the local network.

Rinel-Lingo software allows us to do the following:

1. Demonstrate the image in the computer class and language lab from the teacher's monitor to the monitors of all students or the monitors of a selected group of students. 
2. Show the image from the monitor of any student to the teacher's monitor and the monitors of any group. Simultaneously with viewing the student's screen, the teacher has the ability to control the student's computer.

3. Carry out audio communication between workstations in random audio groups using software methods on a local network.

4. Use and create educational material in the form of multimedia training language laboratories of foreign languages.

Teaching phonetics, educators can use the Lingo-books which are made by the RinelLingo Editor programme. Necessary phonetic material is comprised into this data format that displays parts of the course on the computer. The set of Lingo books gives phonetic material in sequence from easier to more difficult and gives the learners the opportunity to see the tasks, listen to the texts in parts and on the whole, give answers, record themselves and check the results. There are more than 30 ready-made Lingo books in the Rinel-Lingo multimedia language pack, but teachers can also create their own materials using the RinelLingo programme.

Two types of lessons have been designed in this language set. The first type of lessons aims to develop and improve students' listening skills. The second type of lessons is designed to develop other language skills: reading, speaking, and writing.

Learners are allowed to repeatedly listen to the materials in the multimedia class, especially to the challenging one. They have the option to do the exercises orally (to speak in a microphone and, therefore, record themselves in the answer block of this lesson) or in writing (for the tasks where the answer should be printed in the gap). In spite of the prevailing number of linguistic tasks that help master English phonetics (articulation, stress, and intonation), Rinel-Lingo set gives the opportunity to develop students' speaking skills. Monological and dialogical speech can be trained due to the various communicative tasks, for example, when students are to retell the text, describe a picture and record the answer, or make a dialogue in pairs or groups, etc. At the same time, the teacher can listen to any answer, correct it, or give recommendations.

\section{Results of the research}

We have conducted a survey in order to evaluate the benefits of using the Rinel-Lingo programme in teaching English Practical phonetics to second-year students of Murmansk arctic state university. Fifty students studying on the training directions "Pedagogical education. English language. German language" and "Linguistics. Interpreting" were interviewed. The experiment was conducted at the end of 2019. The students had studied Practical phonetics of the English language for a year already before the survey. According to our objective, we were interested to find out the students' attitude to the process of studying Practical phonetics with the help of the language laboratory equipped with multimedia Rinel-Lingo system.

Throughout the first year every Phonetics class the students worked in the language laboratory to practice articulation of sounds and different patterns of intonation. Theoretical material given by the teachers was supplemented with a lot of practical exercises. The learners had an opportunity to work individually, in groups and in pairs, to record their utterances and pay attention to their errors in pronunciation. The teachers could easily control the working process and point out the weak sides of pronunciation.

The study adopted such a research method as the questionnaire since the method is the most suitable for collecting input data and consistent with the goals and objectives of the study. The questionnaire combined open-ended questions and multiple-choice questions with predefined answers offering respondents the possibility to choose and rank among several options or the possibility to grade on a "very low" to "very high" scale. For open- 
ended questions, an optional space was provided to elaborate on the answer. This open part is considered of great importance for a survey of this kind as it contributes to improving the interpretation of its overall results and provides additional valuable material.

The students were asked to write their opinion on the following issues:

1. From your point of view, what educational tools should be used at practical phonetics lessons? Rank the following according to the importance: textbooks, printed materials, oral explanation of an experienced teacher, multimedia laboratory, other options.

2. Has the Rinel-Lingo programme helped you improve your phonetics? Why do you think so?

3. What are the advantages of the multimedia language laboratory, to your mind?

4. From your point of view, what are the negative sides of the Rinel-lingo programme, if any?

5. In your opinion, what should be changed in the programme?

The given questions correlate with the aim of our research and let us find out the students' opinion about the benefits of the language laboratory in studying English phonetics. The respondents took the task seriously and gave full answers. The findings of the questionnaire convinced us that the multimedia approach in the teaching process is considered by the students as necessary and efficient.

Answering the first question, $92 \%$ of the respondents mention that it is not enough to use only textbooks and other printed materials at practical phonetics classes. According to the students' responses, experienced teachers with good command of English are of great importance (ranked first), but even they cannot be the only role-models in developing phonetic skills. From the responders' point of view, multimedia technologies are very helpful (ranked second). It was explained by the fact that the programmes are created by native speakers and can create an artificial linguistic environment for the learners of English. One of the examples is the language laboratory equipped with Rinel-Lingo set, which was considered efficient in learning phonetics.

Analyzing the answers to the second question (Has Rinel-Lingo programme helped you improve your phonetics? Why do you think so?) we could find out that $76 \%$ of the surveyed are sure that Rinel-Lingo programme had helped them improve the level of their phonetics. The students were able to practise the articulation of vowels (monophthongs, diphthongs, and diphthongoids), consonants (labial and lingual and glottal), various sound combinations and their modifications; appropriate pauses that divide the speech into semantic groups; various intonation patterns that bear grammatical function; tempo of utterance; different types of stress (word, phrasal and sentence); English rhythm and other phonetic phenomena. Moreover, the students explained that computer visualization of the aspects of practical phonetics lets them have a better understanding of different issues.

When asked about the positive aspects of the programme, $55 \%$ of students mentioned the opportunity to practise all aspects of phonetics in useful exercises. Rinel Lingo-books structure the linguistic material according to the command of a foreign language of university students, requirements to the correct pronunciation of future linguists and English teachers, and typical phonetic errors made by students who started learning phonetics as a separate subject.

The majority of the respondents added the opportunity to pay attention to the phonological aspect of speech and to work out the following phonation skills of the English language: emotional colouring of speaking, distinctive rhythm and pace of utterance as expressive means, voice power and diction, semantic and logical stress, timbre and semantic pauses.

$20 \%$ of the respondents among positive sides of the multimedia Rinel-Lingo programme stated the option to work in pairs and groups, $25 \%$ emphasized the ability to record themselves and self-control. They explained it by the fact that when you can hear yourself 
doing phonetic exercises, you can understand the weak sides of your pronunciation and intonation and have the opportunity to work them out. Also, the teacher is able to control your work and give some recommendations on how to improve your articulation and intonation.

Among the shortcomings, $20 \%$ of those surveyed said that their own voice is heard in the headphones and this is a little bit distracting, but this mostly applies to the technical side of the equipment. Also, the Rinel-Lingo programme does not let the Internet access in the language laboratory, that can ruin the system.

When asked about possible changes to the programme, $35 \%$ of students noted a lack of up-to-date topics, colourful pictures, and videos in the lessons. Many consider it necessary to update the list of units, to add a modern language to the dialogues and other tasks.

\section{Conclusions}

According to the results of the conducted survey among the second-year students of Murmansk arctic state university, we can conclude that the students find it important and useful to apply multimedia technologies while studying Practical phonetics of the English language.

Organizing the work on the development of phonetic skills of the first-year students at the linguistic departments the teachers are recommended to use the language laboratory based on the Rinel-Lingo multimedia complex which allows making the educational process more efficient. It helps visualize the pronunciation, includes listening to speech in the foreign language, creates an artificial linguistic environment, so the material is perceived easier and faster. What is more, practical phonetics classes become unusual, which increases the interest and motivation of students.

\section{References}

1. V. Zavyalova, Basics of English phonetics (2015)

2. P. Ashby, Understanding phonetics (2013)

3. J.K. Chambers, P. Trudgill, Dialect grammar: Data and theory (Book Chapter) Dialects of English: Studies in Grammatical Variation (2017)

4. A.P.R. Howatt, Language Teaching: History. Encyclopedia of Language \& Linguistics (Second Edition), 634-646 (2006)

5. H.A. Sweet, Handbook of Phonetics: Including a Popular Exposition of the Principles, Cambridge University Press (2013)

6. E.C. Schmid, Potential pedagogical benefits and drawbacks of multimedia use in the English language classroom equipped with interactive whiteboard technology, Computers \& Education, 51(4), 1553-1568 (2008)

7. K. Kozan, G. Erçetin, J.C. Richardson, Input modality and working memory, Effects on second language text comprehension in a multimedia learning environment, 55, 63$73(2015)$

8. F. Atakl1, The Role of Multi-Media in the Foreign Language (Russian) Classroom, Procedia - Social and Behavioral Sciences, 70(25), 795-798 (2013)

9. A. Kemp, Phonetics: Precursors to Modern Approaches, Encyclopedia of Language \& Linguistics (Second Edition), Elsevier Science (2006)

10. G. Dettori, V. Lupi, ICT and new methodologies in language learning, Procedia Social and Behavioral Sciences, 2, 2712-2716 (2010) 
11. A.G. Digor, I.L. Artemeva, E.M. Lukina, V.L. Zavyalova, Instrumental shell for pronunciation training simulator design, Proceedings of the 2nd Russian-Pacific Conference on Computer Technology and Applications (2017)

12. M.F. Hertsch, Multimedia-Based Enrichment for Foreign Language Teaching, Procedia - Social and Behavioral Sciences, 70(25), 615-621 (2013)

13. K. Ying Chan, C. Lyons, L.L. Kon, K. Stine, A. Crossley, Effect of on-screen text on multimedia learning with native and foreign-accented narration, Learning and Instruction, 67, 101305 (2020) 